\title{
Limitations of the Knee Society Score in evaluating outcomes following revision total knee arthroplasty.
}

\author{
Elie Ghanem \\ The Rothman Institute of Orthopaedics, Thomas Jefferson University Hospital \\ Ian Pawasarat \\ The Rothman Institute of Orthopaedics, Thomas Jefferson University Hospital \\ Adam Lindsay \\ The Rothman Institute of Orthopaedics, Thomas Jefferson University Hospital \\ Lauren May \\ The Rothman Institute of Orthopaedics, Thomas Jefferson University Hospital \\ Khalid Azzam \\ The Rothman Institute of Orthopaedics, Thomas Jefferson University Hospital \\ Follow this and additional works at: https://jdc.jefferson.edu/orthofp \\ Part of the Orthopedics Commons

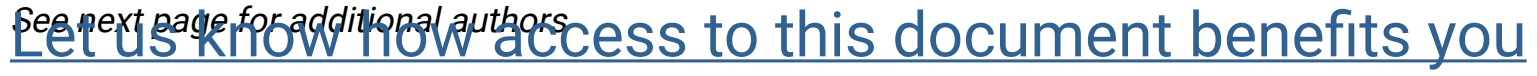

\section{Recommended Citation}

Ghanem, Elie; Pawasarat, lan; Lindsay, Adam; May, Lauren; Azzam, Khalid; Joshi, Ashish; and Parvizi, Javad, "Limitations of the Knee Society Score in evaluating outcomes following revision total knee arthroplasty." (2010). Department of Orthopaedic Surgery Faculty Papers. Paper 28. https://jdc.jefferson.edu/orthofp/28

This Article is brought to you for free and open access by the Jefferson Digital Commons. The Jefferson Digital Commons is a service of Thomas Jefferson University's Center for Teaching and Learning (CTL). The Commons is a showcase for Jefferson books and journals, peer-reviewed scholarly publications, unique historical collections from the University archives, and teaching tools. The Jefferson Digital Commons allows researchers and interested readers anywhere in the world to learn about and keep up to date with Jefferson scholarship. This article has been accepted for inclusion in Department of Orthopaedic Surgery Faculty Papers by an authorized administrator of the Jefferson Digital Commons. For more information, please contact: JeffersonDigitalCommons@jefferson.edu. 


\section{Authors}

Elie Ghanem, Ian Pawasarat, Adam Lindsay, Lauren May, Khalid Azzam, Ashish Joshi, and Javad Parvizi 
The Journal of Bone E Joint Surgery
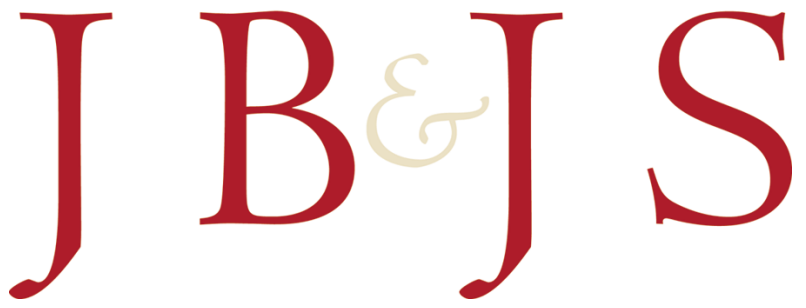

This is an enhanced PDF from The Journal of Bone and Joint Surgery

The PDF of the article you requested follows this cover page.

\section{Limitations of the Knee Society Score in Evaluating Outcomes Following Revision Total Knee Arthroplasty}

Elie Ghanem, Ian Pawasarat, Adam Lindsay, Lauren May, Khalid Azzam, Ashish Joshi and Javad Parvizi J Bone Joint Surg Am. 2010;92:2445-2451. doi:10.2106/JBJS.I.00252

This information is current as of December 1, 2010

Reprints and Permissions

Click here to order reprints or request permission to use material from this article, or locate the article citation on jbjs.org and click on the [Reprints and Permissions] link.

Publisher Information

The Journal of Bone and Joint Surgery

20 Pickering Street, Needham, MA 02492-3157

www.jbjs.org 


\title{
Limitations of the Knee Society Score in Evaluating Outcomes Following Revision Total Knee Arthroplasty
}

\author{
By Elie Ghanem, MD, Ian Pawasarat, MA, Adam Lindsay, MD, Lauren May, MD,
} Khalid Azzam, MD, Ashish Joshi, MD, MPH, and Javad Parvizi, MD, FRCS

Investigation performed at The Rothman Institute of Orthopaedics, Thomas Jefferson University Hospital, Philadelphia, Pennsylvania

\begin{abstract}
Background: Traditionally, the results of revision total knee arthroplasty have been determined with use of surgeonbased measures such as the Knee Society rating system. Recently, outcome and quality-of-life measures have shifted toward a greater emphasis on patient-based evaluation. The aim of our study was to determine the validity and responsiveness of the Knee Society rating system compared with the Short Form-36 health survey (SF-36), Western Ontario and McMaster Universities Osteoarthritis Index (WOMAC), and a four-question 4-point Likert scale satisfaction questionnaire following revision total knee arthroplasty.
\end{abstract}

Methods: A total of 152 patients underwent revision total knee arthroplasty at our institution, between August 2003 and January 2007, and had a two-year follow-up evaluation after revision surgery. The SF-36, WOMAC, Knee Society rating system, and satisfaction scores were completed preoperatively and postoperatively. Spearman correlation coefficients were calculated to determine the degree of correlation for each outcome scale. The SF-36, WOMAC, and patient satisfaction were correlated with the Knee Society rating system.

Results: Both before and after surgery, the correlation among items of the Knee Society rating system displayed low to negligible levels of association. The Knee Society rating system pain score showed modest levels of convergent construct validity with the WOMAC and SF-36. However, the Knee Society functional score displayed negligible to low correlation with its WOMAC functional counterpart preoperatively. The Knee Society pain and functional scores, respectively, showed marked and moderate association with satisfaction. The change in the Knee Society pain and functional scores had moderate association with the SF-36 and WOMAC counterparts, except low correlation was displayed between the pain scores for the Knee Society rating system and the SF-36. The Knee Society rating system pain score was found to be the most responsive of the measures with a standardized response mean of 1.6, whereas the Knee Society rating system functional score was found to be the least responsive at 0.7.

Conclusions: Currently, there is no so-called gold standard that optimally reflects the status of the knee, as well as the patient, prior to and following revision total knee arthroplasty. Ideally, numerous assessment scales should be administered to the patient in order to accurately reflect the patient characteristics for the purpose of academic study, but from a practical standpoint, this may not be feasible. We encourage further research and development of a simple and concise standardized questionnaire for use before and after revision total knee arthroplasty.

$\mathrm{R}$ evision total knee arthroplasty has been shown to be an effective and safe surgical option for the treatment of the failed total knee arthroplasty ${ }^{1,2}$. With an increase in the number of primary total knee arthroplasties being performed, the total number of revisions is expected to rise ${ }^{3}$. One dilemma that faces the orthopaedic community is how to assess patient outcome following these complex procedures. There are currently numerous assessment tools used worldwide for the evaluation of outcome following total knee arthroplasty: the disease-specific tools (the Western Ontario and McMaster Universities Osteoarthritis Index [WOMAC], the McMasterToronto Arthritis Patient Preference Questionnaire, the Knee

Disclosure: The authors did not receive any outside funding or grants in support of their research for or preparation of this work. One or more of the authors, or a member of his or her immediate family, received, in any one year, payments or other benefits in excess of $\$ 10,000$ or a commitment or agreement to provide such benefits from commercial entities (SmartTech and Stryker). 
The Journal of Bone \& Joint Surgery · Jbjs.org Volume 92 -A - Number 14 - OCtober 20, 2010
Limitations of the Knee Society Score in Evaluating Outcomes Following Revision TKA
Society rating system, and the Oxford knee score), global health tools (Short Form-36 [SF-36] health survey), and cost-toutility outcomes tools (quality-adjusted life years) ${ }^{4-11}$. Traditionally, the results of revision surgery have been determined with use of surgeon-based measures such as the Knee Society rating system, although this outcomes tool has never been validated $^{12}$. This issue should soon be addressed as the Knee Society rating system is currently undergoing an update and validation to include objective as well as functional assessments to better reflect patient outcome following knee arthroplasty ${ }^{13}$.

Patient-based questionnaires including the SF-36, the WOMAC, and a Likert satisfaction scale can evaluate the patient's perception of quality of life following revision total knee arthroplast ${ }^{4,14-18}$. Previous studies have examined the correlation among conventional knee scoring systems, general health scores, disease-specific scores, and patient satisfaction after primary total knee arthroplasty ${ }^{19,20}$. Given the complexity of revision total knee arthroplasty and the paucity of studies that have evaluated outcome measures after revision surgery, a thorough analysis of the different survey systems used would be useful $^{21}$.

Since the publication of the Knee Society clinical rating system in 1989, it has been broadly accepted as an objective measure of the knee in patients having total knee arthroplasty ${ }^{12}$. The Knee Society rating system has yet to be validated or shown to be responsive for patients following revision total knee arthroplasty. Although Lingard et al. showed the Knee Society rating system to have adequate convergent construct validity, those authors also stated that the WOMAC and SF-36 are preferable for outcome assessment of total knee arthroplasty as these tools are able to be completed by the patient alone ${ }^{22}$. The aim of our study was to determine the correlation between commonly used outcome questionnaires, specifically those that are used at our institution following revision total knee arthroplasty. We hypothesized that a marked discrepancy exists between the Knee Society rating system and the patientcentered assessment questionnaires (i.e., SF-36, WOMAC, and the satisfaction scale) in reflecting patient outcome.

\section{Materials and Methods}

Collowing institutional review board approval, a thorough

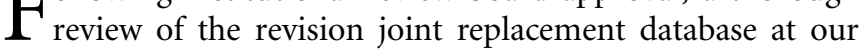
institution was performed to identify patients undergoing revision total knee arthroplasty and extract data for the 304 cases occurring between August 2003 and January 2007. The patients excluded from our final cohort included eighty-five who had a revision because of infection, thirty-five who had a revision for patellar and/or polyethylene exchanges, fifteen who had a revision for conversion of internal fixation or unicompartmental knee replacement to a total knee replacement, and four who had revision for nonprosthetic failure such as retinacular release or extensor mechanism repair. An additional thirteen patients, including nine with failure of the total knee replacement prior to the twenty-four-month follow-up, three who died, and one who was lost to follow-up, were excluded. Our final cohort after exclusion consisted of 152 patients with a mean age of sixty-seven years (range, thirty-six to eighty-nine years) who underwent revision total knee arthroplasty at our institution during the study period and completed preoperative and postoperative assessments. All patients underwent revision total knee arthroplasty because of mechanical failure, including aseptic loosening of total knee arthroplasty components in 106 patients and knee instability in forty-six patients.

There are many possible tools to measure the preoperative as well as postoperative functioning of patients after revision total knee arthroplasty, although at our institution we use the SF-36 for global assessment, the WOMAC for diseasespecific evaluation, the Knee Society rating system for the kneespecific measure, and the satisfaction scale for the patient's impression of the success of the procedure. The SF-36 is a standardized thirty-six-question form used to determine eight dimensions of health (physical functioning, physical role, bodily pain, general health, vitality, social functioning, emotional role, and mental health), which are compiled to form both physical and mental health profiles of the patient, each consisting of 100 points $^{23-25}$. This questionnaire is suited for, and was constructed for, use in health policy evaluations, general population surveys, clinical research and practice, as well as other applications involving a diverse population ${ }^{26}$.

The WOMAC is a disease-specific measure of osteoarthritis in the lower extremities, which consists of three dimensions: pain, stiffness, and function. The WOMAC subscales include five questions on pain for a possible total of 20 points, two questions on stiffness for a possible 8 points, and seventeen questions on function for a possible 68 points, for a total score of 96 points that can be normalized to 100 points in order to facilitate comparison with other questionnaires ${ }^{27}$. The questions surrounding function include items such as "taking off socks/stockings" and "getting in and out of a car." Those relevant to pain include "walking on a flat surface" and "going up or down stairs." Questions regarding stiffness include severity of stiffness in the morning as well as after inactivity later in the day.

The Knee Society score is an assessment of the knee that comprises two arms, the functional ability and clinical examination scores, each with a 100-point denominator. The functional score pertains to the functional capacity of the patient, which includes walking distance, stair-climbing ability, and the use of walking aids. This score is compiled by allocating points for stair-climbing ability and walking distance while making deductions for the use of a walking aid. A Knee Society rating system score of 100 represents unlimited walking distance and normal stair-climbing without the use of a walking aid. The clinical examination score focuses on knee motion, stability, alignment of the knee, and pain ${ }^{28,29}$. This score is composed of 100 points, including 50 points allocated for the evaluation of motion, stability, and alignment and 50 points allocated for pain. The physical examination portion is based on the knee motion, stability, and alignment; a score of 50 indicates a minimum knee movement of $0^{\circ}$ to $125^{\circ}$, without an active extension lag, without instability, and possessing normal mechanical axis alignment. Of the 50 points allocated for pain, 
The Journal of Bone \& Joint Surgery $\cdot$ Jbjs.org Volume 92 -A • Number $14 \cdot$ OCtober 20, 2010
Limitations of the Knee Society Score in Evaluating

Outcomes Following Revision TKA

\section{TABLE I Mean Preoperative and Postoperative Outcome Scores and Standardized Response Mean}

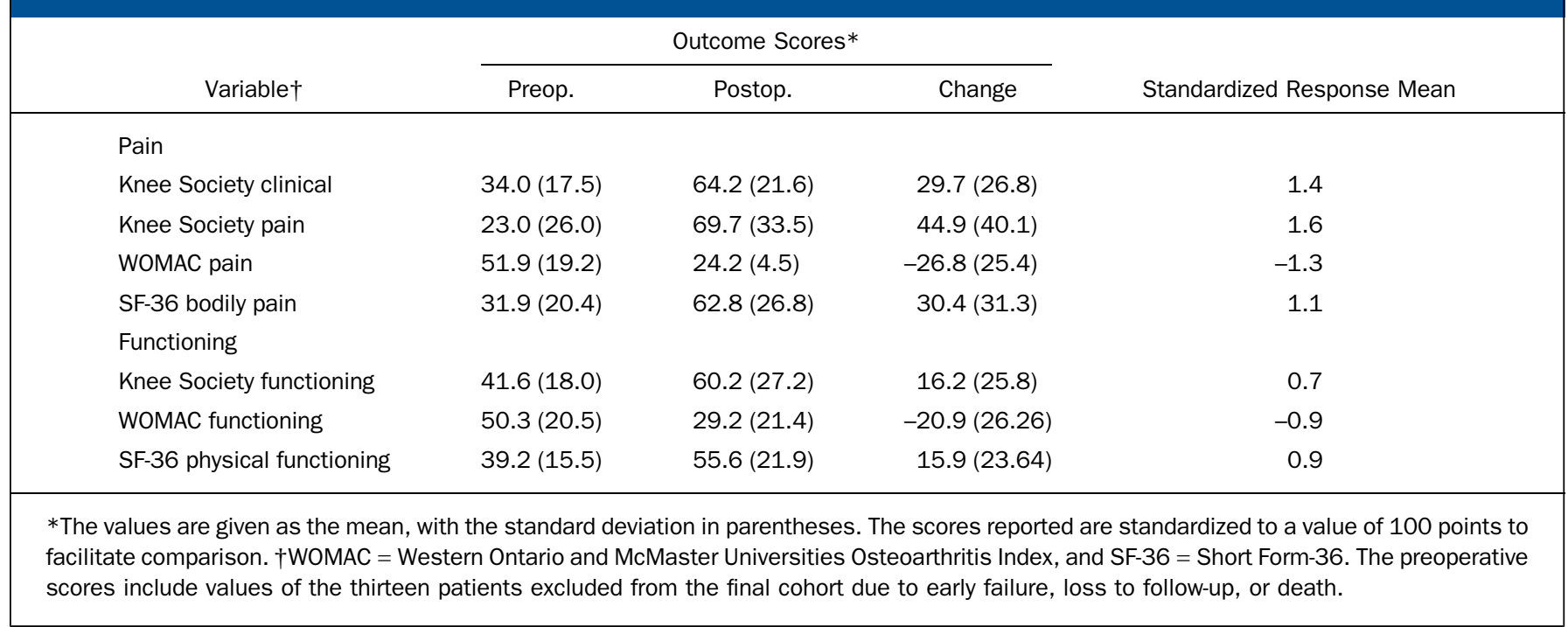

points are deducted with increasing frequency and severity of pain. Pain is evaluated in a single question, which may be answered with one of seven responses, indicating varying levels of pain intensity and frequency.

Patient satisfaction with the outcome of the revision total knee arthroplasty was determined with use of a previously validated four-question 4-point Likert scale ${ }^{14,15,17}$. This survey includes questions regarding patient satisfaction with pain relief, improvement in function in the home and during recreation, and overall satisfaction with the procedure. The total satisfaction score is calculated as a mean of the responses to the four questions and then is converted to a 100-point scale, with 100 representing the highest level of satisfaction. Patients were considered to be very satisfied if the score was $>75$, satisfied if the score was $>50$ and $\leq 75$, dissatisfied if the score was $>25$ and $\leq 50$, and very dissatisfied if it was $\leq 25$.
Preoperative baseline forms, including the SF-36, WOMAC, and Knee Society rating system, were completed by patients and physicians at a maximum of six weeks prior to revision surgery. At the two-year follow-up visit, the SF-36, the WOMAC, and the satisfaction questionnaire were completed by the patient while their surgeon completed the Knee Society rating system forms after evaluating the patient and the postoperative radiographs. The surgeon was blinded to patient responses during the preoperative and postoperative evaluation.

\section{Statistical Analysis}

The means and standard deviations were calculated for each outcome measure and compared with use of the test. Spearman correlation coefficients were calculated to determine the extent of correlation of the different subscales and dimensions of the SF-36 and WOMAC with the clinical and

TABLE II Correlations Among Items of the Clinical Score*

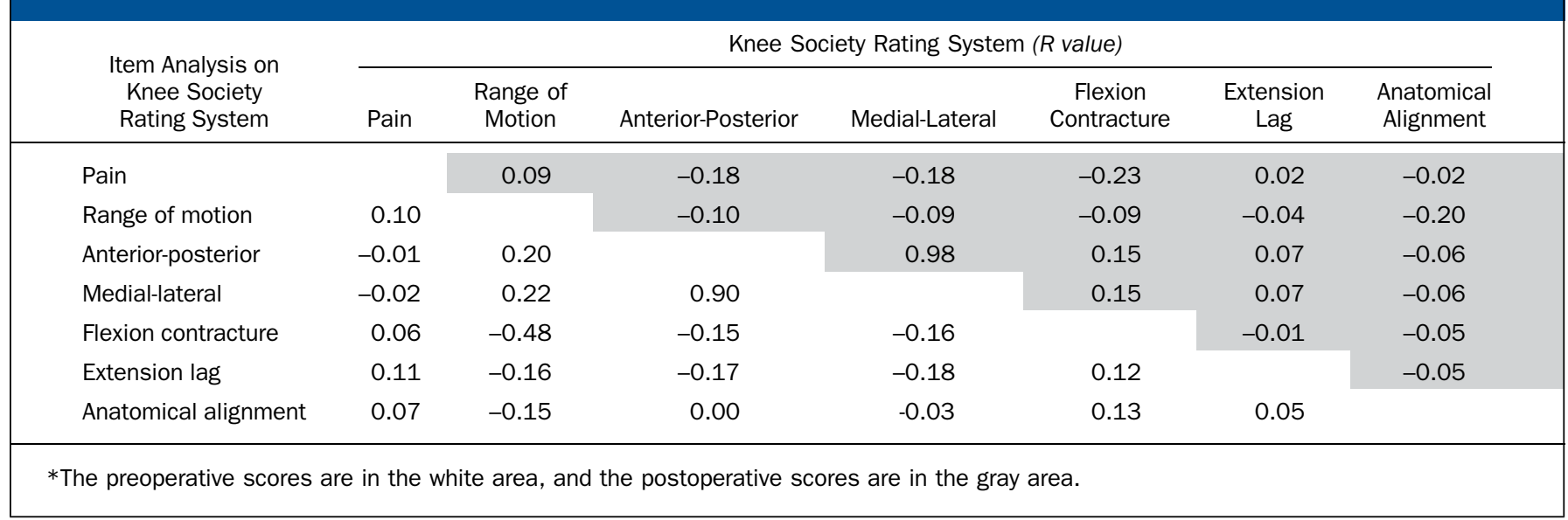


The Journal of Bone \& Joint Surgery · Jbjs.org Volume 92-A • Number 14 - October 20, 2010
Limitations of the Knee Society Score in Evaluating Outcomes Following Revision TKA

\begin{tabular}{|c|c|c|c|}
\hline \multirow[b]{2}{*}{ Item } & \multicolumn{3}{|c|}{$\begin{array}{c}\text { Knee Society } \\
\text { Rating System ( } R \text { value) }\end{array}$} \\
\hline & $\begin{array}{l}\text { Walking } \\
\text { Aid }\end{array}$ & $\begin{array}{l}\text { Stair } \\
\text { Climbing }\end{array}$ & $\begin{array}{l}\text { Walking } \\
\text { Distance }\end{array}$ \\
\hline Walking aid & & -0.44 & -0.45 \\
\hline Stair climbing & -0.37 & & 0.63 \\
\hline Walking distance & -0.33 & 0.36 & \\
\hline
\end{tabular}

functional Knee Society rating system scores at the preoperative and the two-year postoperative period. A similar analysis was performed for the change in score from baseline to follow-up evaluation for the above-mentioned assessment forms. The strength of correlation was indicated by an $\mathrm{r}$ value, with 0 to 0.20 indicating negligible; 0.21 to 0.40 , low; 0.41 to 0.60 , moderate; 0.61 to 0.80 , marked; and 0.81 to 1.00 , high correlation. A p value of $<0.05$ was considered to be significant. Responsiveness was assessed with use of standardized response means, which are calculated by dividing the mean change from the preoperative state by the standard deviation of the change in score ${ }^{30}$.

\section{Source of Funding}

There was no external source of funding for this study.

\section{Results}

$A^{t}$ the two-year follow-up evaluation, the mean postoperative scores of the SF-36, WOMAC, and Knee Society rating system showed improvement from the baseline levels (Table I). All reported $\mathrm{r}$ values below depicting correlations among the Knee Society rating system, WOMAC, SF-36 scores, and satisfaction scores were found to be significant $(\mathrm{p}<0.01)$.

\section{Item Analysis}

Preoperatively, the level of correlation among the clinical items of the Knee Society rating system were characterized as negligible to low, except for anterior-posterior and medial-lateral stability, which displayed a high level of correlation, and flexion contracture, which displayed a moderate level of correlation (Table II). Postoperatively, similar negligible to low levels of correlation among most Knee Society rating system items were seen, although anterior-posterior and medial-lateral stability again displayed a high degree of association. The Knee Society rating system functional ability scores showed low correlation preoperatively and moderate to marked correlation postoperatively (Table III).

\section{Validity}

The preoperative and postoperative correlations of the Knee Society rating system, WOMAC, SF-36, and satisfaction scores are shown in Table IV. As there is currently no validated means of assessing the clinical measurements (range of motion, alignment, and stability), it was impossible to test for convergent construct validity for the above parameters ${ }^{22}$. The preoperative Knee Society pain score showed a low degree of correlation with the WOMAC pain score but a moderate level of association with the SF-36 pain score. Interestingly, the postoperative assessments show marked association of the Knee Society rating system pain score with the WOMAC pain score but only moderate correlation with the SF-36 pain score. Satisfaction also displayed a marked association with the postoperative Knee Society pain score (Table IV).

The preoperative functional scores for the Knee Society rating system displayed a negligible degree of association with the WOMAC functional score and a low level of association with the SF-36 functional score. The postoperative functional scores for the Knee Society rating system displayed a marked

TABLE IV Correlation Among the Knee Society Rating System, WOMAC, SF-36, and Satisfaction Scores*

\begin{tabular}{|c|c|c|c|c|c|c|c|c|}
\hline & \multicolumn{3}{|c|}{ Knee Society Rating System } & \multicolumn{2}{|c|}{ WOMAC } & \multicolumn{2}{|c|}{ SF-36 } & Satisfaction \\
\hline Knee Society function & 0.16 & & 0.33 & -0.74 & -0.60 & 0.85 & 0.49 & 0.42 \\
\hline Knee Society clinical & 0.79 & 0.30 & & -0.47 & -0.54 & 0.40 & 0.46 & 0.49 \\
\hline WOMAC function & -0.28 & -0.19 & -0.24 & & 0.83 & -0.81 & -0.62 & -0.60 \\
\hline SF-36 function & 0.18 & 0.30 & 0.16 & -0.44 & -0.27 & & 0.66 & 0.51 \\
\hline SF-36 pain & 0.45 & 0.21 & 0.36 & -0.57 & -0.65 & 0.46 & & 0.42 \\
\hline
\end{tabular}


The Journal of Bone \& Joint Surgery · Jbjs.org Volume 92 -A • Number 14 - OCtober 20, 2010
Limitations of the Knee Society Score in Evaluating

Outcomes Following Revision TKA

TABLE V Correlation of the Change Among the Knee Society Rating System, WOMAC, SF-36, and Satisfaction Scores*

\begin{tabular}{|c|c|c|c|c|c|c|c|}
\hline & \multicolumn{3}{|c|}{ Knee Society Rating System } & \multicolumn{2}{|c|}{ WOMAC } & \multicolumn{2}{|c|}{ SF-36 } \\
\hline Knee Society clinical & 0.81 & & & & & & \\
\hline Knee Society function & 0.36 & 0.34 & & & & & \\
\hline WOMAC pain & -0.47 & -0.36 & -0.42 & & & & \\
\hline SF-36 pain & 0.39 & 0.35 & 0.43 & -0.51 & -0.56 & & \\
\hline SF-36 function & 0.26 & 0.20 & 0.56 & -0.38 & -0.62 & 0.54 & \\
\hline Satisfaction & 0.57 & 0.45 & 0.45 & -0.53 & -0.46 & 0.35 & 0.30 \\
\hline
\end{tabular}

association with the functional WOMAC, a high degree of correlation with the functional SF-36, and a moderate degree of correlation with satisfaction (Table IV).

\section{Responsiveness}

The responsiveness of the Knee Society rating system was evaluated through comparison of the correlation coefficients among the changes in the Knee Society rating system, WOMAC, and SF-36 as well as postoperative patient satisfaction (Table V). The change in the Knee Society rating system pain score displayed a moderate level of correlation with the change in the WOMAC pain score $(-0.47)$ and a low level of association with the change in the SF-36 pain score (0.39). Although the level of correlation between the change in the WOMAC and SF-36 pain scores $(-0.51)$ is higher than that between the WOMAC and Knee Society rating systems $(-0.47)$, both are classified as moderate correlation. Correlation of the change in the Knee Society functional score with the functional scores of the WOMAC $(-0.51)$ and SF-36 (0.56) displayed a moderate degree of association. The change in the WOMAC functional score and the change in the SF-36 functional score displayed a higher level of association, reaching a marked level of correlation $(-0.62)$, than either did with the change in the Knee Society rating system. Satisfaction showed moderate association with the changes in WOMAC and Knee Society rating system scales for function but low association with the changes in SF-36 score for function (Table V).

We calculated the standardized response means for each of the outcome measures for the pain and functional scores, after exclusion of the patients reporting dissatisfaction following the revision procedure. This analysis showed that the most responsive tool for assessing pain is the Knee Society rating system, which had a standardized response mean of 1.6 compared with 1.3 for the WOMAC and 1.1 for the SF-36 (Table I). With regard to the functional scores, the Knee Society rating system was shown to be the least responsive at 0.7 compared with 0.9 for both the WOMAC and the SF-36.

\section{Discussion}

Traditionally, the outcome of total knee arthroplasty has $I$ been evaluated with use of physician-based scales ${ }^{12}$. Recently, an increasing amount of emphasis has been placed on the use of patient-based measures of surgical outcome that can accurately reflect patient satisfaction and improvement. The determination of which outcome measures to use has been fueled by evidence suggesting the existence of disparities between physician and patient perception of success. Lieberman et al. reported significant differences in patient and physician evaluation of pain and satisfaction after total hip arthroplasty ${ }^{31}$. The general assessment of physical and mental health as well as comorbidities of the patient are important variables that come into play in the evaluation of a patient with a clinically functional knee ${ }^{32}$, and these factors are often lacking in the surgeonbased measurement tools.

In an effort to increase the accuracy and completeness of patient outcome measures, many investigators have chosen to combine various outcome questionnaires when evaluating patients after a revision total knee arthroplasty ${ }^{1,2,21}$. However, to date, there is no so-called gold standard for this measurement. While patient self-reported measures of outcome such as the SF-36, the WOMAC, and the four-question 4-point Likert scale for patient satisfaction have previously been validated, the Knee Society clinical rating system has yet to be validated, particularly for patients after revision total knee arthroplasty, ${ }^{4,14-17,19,20,22,26,33}$.

Lingard et al. claimed the face validity of the Knee Society rating system is questionable, as patients were not included in the item-selection process and the number of selected items is limited $^{22}$. In the same study, it was also demonstrated that the physical examination score is subject to misrepresentative scores, as poor correlation among the items of the clinical score on the Knee Society rating system make it possible for two very different patients to receive the same score. For example, a patient who presents with an extremely stiff, pain-free, well-aligned knee will receive a score similar to a patient with mild pain, excellent knee motion, and normal alignment. These are clearly very different 
The Journal of Bone \& Joint Surgery · JBJS. Org Volume 92-A • Number $14 \cdot$ OCtober 20, 2010
Limitations of the Knee Society Score in Evaluating Outcomes Following Revision TKA patients as the first would have difficulty with everyday tasks such as getting into and out of a car, whereas the second would have little difficulty with these tasks. Is too much being measured to be reported in a single score? Should the Knee Society rating system scores be reported in a manner akin to the Harris hip score, which reports pain as its own value? Interestingly, at our institution, we found that the components of the Knee Society functional score had much higher postoperative intercorrelation, with moderate to marked correlation, than the Knee Society pain and clinical components, which had predominantly negligible intercorrelation.

To validate the construct of a given test, it is necessary for the scores of the test under investigation to positively correlate with the gold standard. For the knee with no such standard, we are left to measure the pain and functional components of the Knee Society rating system against those of the WOMAC and SF-36. There is a caveat for the WOMAC, as a better score on the WOMAC is the score closer to zero; hence, the Knee Society rating system must negatively correlate. Correlation coefficients for convergent construct validity are often in the range of 0.2 to 0.6 , and infrequently are they $>0.7^{34}$. It should be noted that, even in doing this, the whole of the Knee Society rating system will remain not validated for revision patients as there is no clinical scale to measure against for instability, range of motion, extension lag, and flexion contracture.

The pain component of the Knee Society rating system preoperatively correlated more strongly with the SF-36 (0.45) than with the WOMAC $(-0.37)$. This is interesting as the Knee Society rating system was intended for patients undergoing total knee arthroplasty, while the WOMAC was intended for patients with painful osteoarthritis of the knee or hip. However, the SF-36 possesses a more general assessment for bodily pain. The postoperative values were much more in line with what was expected as the Knee Society rating system correlated more highly with the WOMAC $(-0.69)$ than with the SF-36 (0.52). Given these values and the guidelines established by McDowell and Newell, we can categorize the strength of the convergent construct validity as modest ${ }^{34}$.

The functional component of the Knee Society rating system preoperatively correlated more strongly with the SF-36 $(0.21)$ than with the WOMAC $(-0.19)$, which may call into question the preoperative validity of the functional Knee Society rating system as per McDowell and Newell ${ }^{34}$. Postoperatively, a similar theme arose as the Knee Society rating system again correlated more highly with the SF-36 (0.85) than with the WOMAC $(-0.74)$. This is similar to the findings in the primary total knee arthroplasty validation process and, as discussed by Lingard et al., is likely due to the similarity of the questions regarding function for the SF-36 and Knee Society rating system, which predominantly concern stairs and walking ability $^{22}$. Given that the preoperative correlations of the Knee Society rating system subscales with the WOMAC and the SF-36 were lower than the postoperative associations, this indicates that the Knee Society rating system is not able to adequately measure the true preoperative status of the knee in a patient requiring revision total knee arthroplasty. Another possibility is that the Knee Society rating system is surgeon rated and as such the inherent bias of the rater may lead to lower scores. Furthermore, the SF-36 does not focus on the pain that is specific to an orthopaedic procedure but on bodily pain in general, while the WOMAC attributes pain to either the hip or knee joint.

Responsiveness was gauged with use of standardized response means. Congruent with the previous findings in primary total knee arthroplasty ${ }^{22}$, we found that the Knee Society rating system for pain was shown to be the most responsive with a value of 1.6 compared with 1.3 for the WOMAC and 1.1 for the SF-36, despite the fact that the WOMAC was expected to be the most responsive with the greater depth of questions regarding pain. Conversely, the responsiveness of the Knee Society rating system with regard to function was shown to be the least at 0.7, while the WOMAC and the SF-36 tied at 0.9. This is congruent with the previously reported decreased responsiveness of the Knee Society rating system compared with the SF-36 and WOMAC ${ }^{22}$.

Patient satisfaction following surgery was also analyzed to assess responsiveness of the above measures by correlation. Moderate correlation was shown to exist between satisfaction and the Knee Society clinical, pain, and functional assessments as well as the WOMAC pain and functional components. A lesser degree of association (low correlation) occurred between satisfaction and the SF-36 pain and functional scores. This is logical as the satisfaction index focuses on the knee, as do both the WOMAC and the Knee Society rating system, while the SF36 is a more general assessment.

Although the construct of our study is sound and thorough, there are a few limitations worth noting. Our analysis of patients did not include a measure of patient expectations that has previously been noted to have a profound impact on patient expectations ${ }^{35}$. Furthermore, our study was conducted at a single institution and as such may lack generalizability. However, a substantial portion of the patients having a revision came from other hospitals. Our study has similar findings to those from the assessment of primary total knee arthroplasty. Although we feel confident in our evaluation of the Knee Society rating system as both valid and responsive in its ability to gauge the pain of the revised knee, there are concerns that the Knee Society rating system does not adequately assess the preoperative functional state because of the low level of association with the WOMAC. We believe this to be a weakness of the Knee Society rating system as it is not able to adequately represent the possible breadth of the general state of patients following the failed total knee replacement. Currently, there continues to be no gold standard that optimally reflects the status of the knee as well as the patient prior to and following revision total knee arthroplasty. Ideally, numerous assessment scales should be administered to the patient in order to accurately reflect the patient characteristics for the purposes of academic study, but from a practical standpoint this may not be feasible. We encourage further research and development of a simple and concise standardized questionnaire for use before and after revision total knee arthroplasty. 
The Journal of Bone \& Joint Surgery $\cdot$ JBjS. org Volume 92-A • Number $14 \cdot$ OCtober 20, 2010
Limitations of the Knee Society Score in Evaluating Outcomes Following Revision TKA
Elie Ghanem, MD

Ian Pawasarat, MA

Adam Lindsay, MD

Lauren May, MD

Khalid Azzam, MD

Ashish Joshi, MD, MPH
Javad Parvizi, MD, FRCS

Joint Reconstructive Research,

The Rothman Institute of Orthopaedics,

Thomas Jefferson University Hospital,

925 Chestnut Street, 2nd Floor, Philadelphia, PA 19107.

E-mail address for J. Parvizi: Parvj@aol.com

\section{References}

1. Saleh KJ, Celebrezze M, Kassim R, Dykes DC, Gioe TJ, Callaghan JJ, Salvati EA. Functional outcome after revision hip arthroplasty: a metaanalysis. Clin Orthop Relat Res. 2003;416:254-64.

2. Sheng P, Lehto M, Kataja M, Halonen P, Moilanen T, Pajamaki J. Patient outcome following revision total knee arthroplasty: a meta-analysis. Int Orthop. 2004;28: 78-81.

3. Lavernia C, Lee DJ, Hernandez VH. The increasing financial burden of knee revision surgery in the United States. Clin Orthop Relat Res. 2006;446:221-6.

4. Bellamy N, Buchanan WW, Goldsmith $\mathrm{CH}$, Campbell J, Stitt LW. Validation study of WOMAC: a health status instrument for measuring clinically important patient relevant outcomes to antirheumatic drug therapy in patients with osteoarthritis of the hip or knee. J Rheumatol. 1988;15:1833-40.

5. McHorney CA, Haley SM, Ware JE Jr. Evaluation of the MOS SF-36 Physical Functioning Scale (PF-10): II. Comparison of relative precision using Likert and Rasch scoring methods. J Clin Epidemiol. 1997;50:451-61.

6. McHorney CA, Ware JE Jr. Construction and validation of an alternate form general mental health scale for the Medical Outcomes Study Short-Form 36-Item Health Survey. Med Care. 1995;33:15-28.

7. Räsänen $P$, Paavolainen $P$, Sintonen $H$, Koivisto $A M$, Blom $M$, Ryynänen $O P$, Roine RP. Effectiveness of hip or knee replacement surgery in terms of qualityadjusted life years and costs. Acta Orthop. 2007;78:108-15.

8. Conaghan PG, Emerton M, Tennant A. Internal construct validity of the Oxford Knee Scale: evidence from Rasch measurement. Arthritis Rheum. 2007;57:1363-7.

9. Tugwell P, Bombardier C, Buchanan WW, Goldsmith $\mathrm{CH}$, Grace E, Hanna B. The MACTAR Patient Preference Disability Questionnaire-an individualized functional priority approach for assessing improvement in physical disability in clinical trials in rheumatoid arthritis. J Rheumatol. 1987;14:446-51.

10. Barrack RL, McClure JT, Burak CF, Clohisy JC, Parvizi J, Sharkey P. Revision total knee arthroplasty: the patient's perspective. Clin Orthop Relat Res. 2007;464: 146-50.

11. Dahm DL, Barnes SA, Harrington JR, Berry DJ. Patient reported activity after revision total knee arthroplasty. J Arthroplasty. 2007;22(6 Suppl 2):106-10.

12. Insall JN, Dorr LD, Scott RD, Scott WN. Rationale of the Knee Society clinical rating system. Clin Orthop Relat Res. 1989;248:13-4.

13. Scuderi G, Benjamin J, Lonner J, Bourne B, Scott N. The Knee Society. http:// www.kneesociety.org/web/outcomes. html. Accessed 2007 Sep 3.

14. Mahomed N, Sledge CB, Daltroy L, Fossel AH, Katz JN. Self-administered patient satisfaction scale for joint replacement arthroplasty. Read at the Annual Meeting of the Canadian Orthopaedic Association; 1997 May 31; Hamilton, ON.

15. Katz JN, Phillips CB, Baron JA, Fossel AH, Mahomed NN, Barrett J, Lingard EA, Harris WH, Poss R, Lew RA, Guadagnoli E, Wright EA, Losina E. Association of hospital and surgeon volume of total hip replacement with functional status and satisfaction three years following surgery. Arthritis Rheum. 2003;48:560-8.

16. McHorney CA, Ware JE Jr, Raczek AE. The MOS 36-Item Short-Form Health Survey (SF-36): II. Psychometric and clinical tests of validity in measuring physical and mental health constructs. Med Care. 1993;31:247-63.

17. Mahomed N, Sledge CB, Daltroy LH, Fossel AH, Katz JN. Self-administered satisfaction scale for joint replacement arthroplasty. J Bone Joint Surg Br. 1998; 80(Suppl 1):9.
18. Mahomed NN, Liang MH, Cook EF, Daltroy LH, Fortin PR, Fossel AH, Katz JN. The importance of patient expectations in predicting functional outcomes after total joint arthroplasty. J Rheumatol. 2002;29:1273-9.

19. Anderson JG, Wixson RL, Tsai D, Stulberg SD, Chang RW. Functional outcome and patient satisfaction in total knee patients over the age of 75 . J Arthroplasty. 1996;11:831-40

20. Robertsson O, Dunbar MJ. Patient satisfaction compared with general health and disease-specific questionnaires in knee arthroplasty patients. J Arthroplasty. 2001;16:476-82.

21. Mulhall KJ, Ghomrawi HM, Bershadsky B, Saleh KJ. Functional improvement after total knee arthroplasty revision: new observations on the dimensional nature of outcome. J Orthop Surg Res. 2007;2:25.

22. Lingard $E A$, Katz JN, Wright RJ, Wright $E A$, Sledge CB; Kinemax Outcomes Group. Validity and responsiveness of the Knee Society Clinical Rating System in comparison with the SF-36 and WOMAC. J Bone Joint Surg Am. 2001;83:1856-64.

23. Brazier J, Jones N, Kind $P$. Testing the validity of the Eurogol and comparing it with the SF-36 health survey questionnaire. Qual Life Res. 1993;2:169-80.

24. Brazier JE, Harper R, Jones NM, O'Cathain A, Thomas KJ, Usherwood T, Westlake L. Validating the SF-36 health survey questionnaire: new outcome measure for primary care. BMJ. 1992;305:160-4.

25. Jenkinson C, Coulter A, Wright L. Short Form 36 (SF36) health survey ques tionnaire: normative data for adults of working age. BMJ. 1993;306:1437-40.

26. McHorney CA, Ware JE Jr, Lu JF, Sherbourne CD. The MOS 36-item Short-Form Health Survey (SF-36): III. Tests of data quality, scaling assumptions, and reliability across diverse patient groups. Med Care. 1994;32:40-66.

27. Angst $F$, Ewert $T$, Lehmann $S$, Aeschlimann $A$, Stucki $G$. The factor subdimensions of the Western Ontario and McMaster Universities Osteoarthritis Index (WOMAC) help to specify hip and knee osteoarthritis. A prospective evaluation and validation study. J Rheumatol. 2005;32:1324-30.

28. Liow RY, Walker K, Wajid MA, Bedi G, Lennox CM. The reliability of the American Knee Society Score. Acta Orthop Scand. 2000;71:603-8.

29. Liow RY, Walker K, Wajid MA, Bedi G, Lennox CM. Functional rating for knee arthroplasty: comparison of three scoring systems. Orthopedics. 2003;26:143-9.

30. Liang MH, Fossel AH, Larson MG. Comparisons of five health status instruments for orthopedic evaluation. Med Care. 1990;28:632-42.

31. Lieberman JR, Dorey F, Shekelle P, Schumacher L, Thomas BJ, Kilgus DJ, Finerman GA. Differences between patients' and physicians' evaluations of outcome after total hip arthroplasty. J Bone Joint Surg Am. 1996;78:835-8.

32. König $A$, Scheidler M, Rader C, Eulert J. The need for a dual rating system in total knee arthroplasty. Clin Orthop Relat Res. 1997;345:161-7.

33. McHorney CA, Ware JE Jr, Rogers W, Raczek AE, Lu JF. The validity and relative precision of MOS short- and long-form health status scales and Dartmouth COOP charts. Results from the Medical Outcomes Study. Med Care. 1992;30(5 Suppl): MS253-65.

34. McDowell I, Newell C. Measuring health: a guide rating scales and questionnaires. Toronto: Oxford University Press; 1987.

35. Lingard EA, Sledge CB, Learmonth ID; Kinemax Outcomes Group. Patient expectations regarding total knee arthroplasty: differences among the United States, United Kingdom, and Australia. J Bone Joint Surg Am. 2006;88:1201-7. 